\title{
Anesthetic manipulation in extreme airway stenosis: a case report
}

\author{
Zhi-Bin Zhou, Xiao-Yu Yang, Xue Zhou, Shi-Hong Wen, Ying Xiao and Xia Feng*
}

\begin{abstract}
Introduction: Anesthetic management with airway stenosis is challenging. Techniques for maintaining spontaneous respiration are required under sedative and analgesic conditions.

Case presentation: A 35-year-old Chinese woman presented to our hospital with difficulty breathing. Computerized tomography showed a tumor in the frontal area of her neck, which was causing extreme narrowing of her trachea. She was immediately scheduled for emergency surgery to remove the tumor. Fiberscopic intubation was carefully performed with dexmedetomidine sedation and remifentanil analgesia. Spontaneous respiration was successfully maintained.

Conclusion: In cases of extreme airway stenosis, intubation can be safely achieved with dexmedetomidine sedation and remifentanil analgesia.
\end{abstract}

\section{Introduction}

Anesthetic management in cases of airway stenosis is challenging, and it is crucial to fully evaluate the airway preoperatively. Plain computerized tomography (CT), chest X-ray, laryngoscopy and further pulmonary function tests are often employed to assess airway condition. Techniques for maintaining spontaneous respiration under sedative and analgesic conditions are required. Most sedatives and analgesics suppress respiration and put such patients in peril.

We managed a patient whose airway was severely narrowed due to the metastasis of a thyroid tumor. Sedative intubation was attempted and successfully accomplished with a fiberscope.

\section{Case presentation}

A 35 -year-old Chinese woman (weight $56 \mathrm{~kg}$, height $158 \mathrm{~cm}$ ) discovered a lump on the anterior surface of her neck one month prior to her presentation. Thereafter, she progressively developed difficulty swallowing and breathing. A CT scan and X-ray indicated metastasis of thyroid cancer in and around her trachea, encompassing most of the anterior cervical region and compressed her trachea and esophagus to the left, leaving only a very narrow airway (Figures 1 and 2).

\footnotetext{
* Correspondence: fengxia@mail.sysu.edu.cn

Department of Anesthesiology, First Affiliated Hospital of Sun Yat-Sen University, No. 58 Zhongshan 2nd Road, Guangzhou 510080, PR China
}

Surgery to remove the tumor and reconstruct the airway was immediately required. However, the major difficulty facing our surgical team was the method for safely establishing an airway before anesthesia. Because the tumor was primarily located at the $\mathrm{C} 7$ to $\mathrm{T} 2$ level, a tracheotomy could not be performed. Our patient had a Mallampati class zero airway, a thyromental distance of $5 \mathrm{~cm}$ wide and a mouth opening of $4 \mathrm{~cm}$ wide. We expected little difficulty exposing her vocal cord. According to the CT measurement of the narrowest section of airway opening, an endotracheal tube with inner diameter $5.0 \mathrm{~mm}$ was chosen to ensure passage of the tube.

Dexmedetomidine and target controlled infusion (TCI) remifentanil were infused at rates of $0.5 \mu \mathrm{g} / \mathrm{kg} / \mathrm{h}$ and $3 \mathrm{ng} / \mathrm{ml}$, respectively. Topical anesthesia was applied with $2 \%$ lidocaine over her nasopharynx, oral pharynx and laryngopharynx. After 25 minutes, she was properly sedated to endure airway stimulation. Nasal fiberscopic endotracheal intubation was attempted and achieved in spite of a contorted, difficult airway. The tumor under the vocal cord was rubbery with a mobile nature. Spontaneous respiration was maintained successfully. No hypoxia or adverse airway reflex was noted during the procedure. Vital signs were stable (Figure 3). After confirmation of successful airway establishment, sevoflurane inhalation and intravenous propofol were quickly administered to deepen her sedation level. A muscle relaxant 


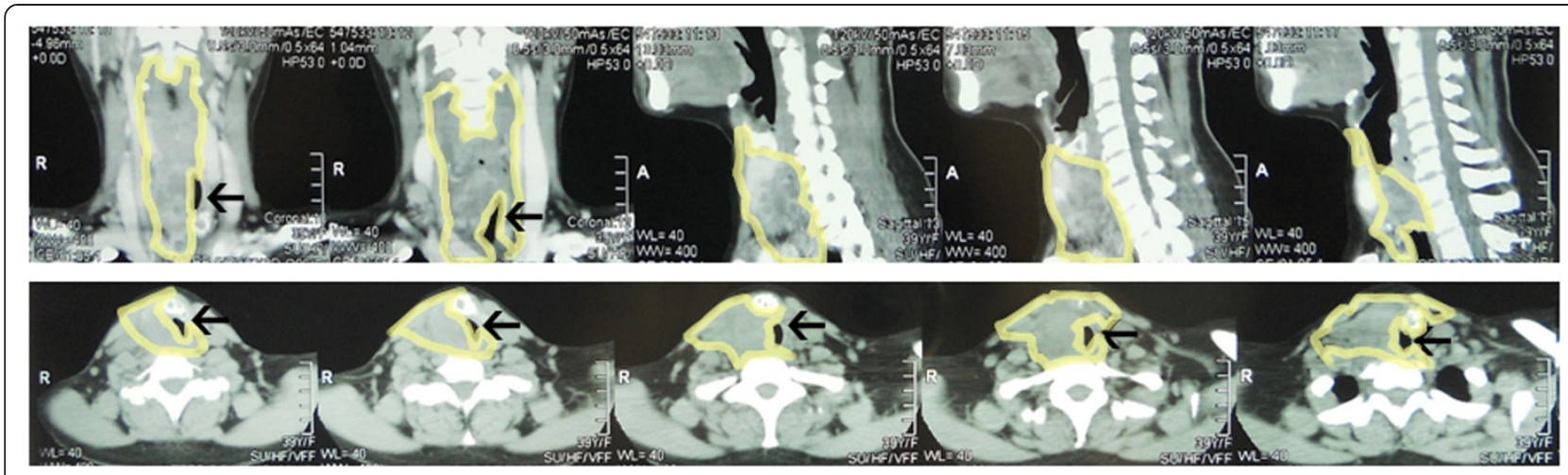

Figure 1 Computerized tomography scan showed severe stenosis of the airway. The area within the yellowish border denotes the distribution of the tumor. The remaining airway is indicated by the black arrow.

was provided to facilitate mechanical ventilation. The subsequent tumor removal surgery was performed and patient woke up breathing with ease.

\section{Discussion}

Preoperative evaluation of the airway is essential in patients with an abnormal airway. Multi-slice CT, which can be reconstituted with three-dimensional (3D) images, can provide a virtual bronchoscopic view [1]. However, because our patient presented as an emergency case, a 3D-image reconstruction was not performed. All efforts were made to release the airway obstruction as soon as possible.

When confronted with a difficult airway before general anesthesia, the most routine maneuver is awake intubation. In awake intubation, no neuromuscular blocking drug is administered to minimize the risk of a failed airway. However, the entire process is too distressing, because only topical anesthesia of the nasal and laryngeal area is applied. With proper sedation, the procedure is more tolerable. The commonly used sedatives include propofol, sevoflurane and dexmedetomidine. Sevoflurane is equivalent to propofol for the performance of fiberoptic intubation under spontaneous respiration in terms of the success rate, patient recall and satisfaction [2]. However both sevoflurane and propofol suppress respiration to a certain extent; if not skillfully titrated individually, patients will either be agitated or the airway easily compromised [3]. In a study that compared propofol with dexmedetomidine for sedation during fiberoptic nasal intubation, patients in the dexmedetomidine group experienced a lower heart-rate response to intubation, showed better tolerance, and had a more stable hemodynamic status [4].

In addition to sedation, remifentanil can be used to relieve pain and blunt nerve reflexes during intubation. Because of its short duration of action, the risk of respiratory depression is minimized. In our previous study [5], TCI remifentanil and TCI propofol were compared in awake fiberoptic intubation. TCI remifentanil at $4 \mathrm{ng} / \mathrm{mL}$ provided better conditions for opening the vocal cord and shortened the duration of the intubation procedure. As a result, in this case, we used dexmedetomidine and

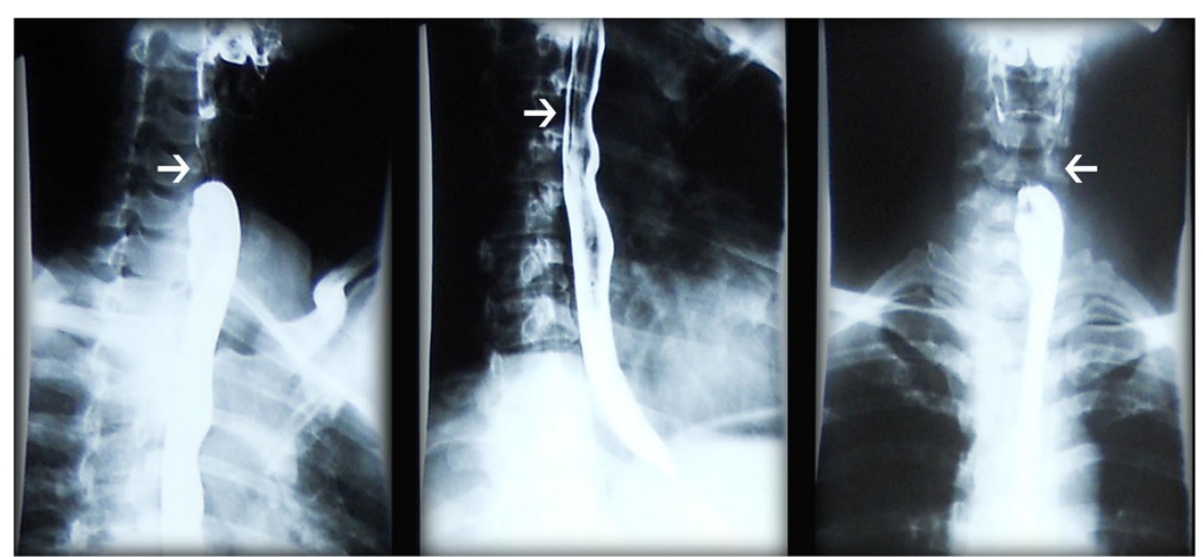

Figure 2 X-ray showed compression of the esophagus. The white arrow indicates the compressed part of the esophagus. 


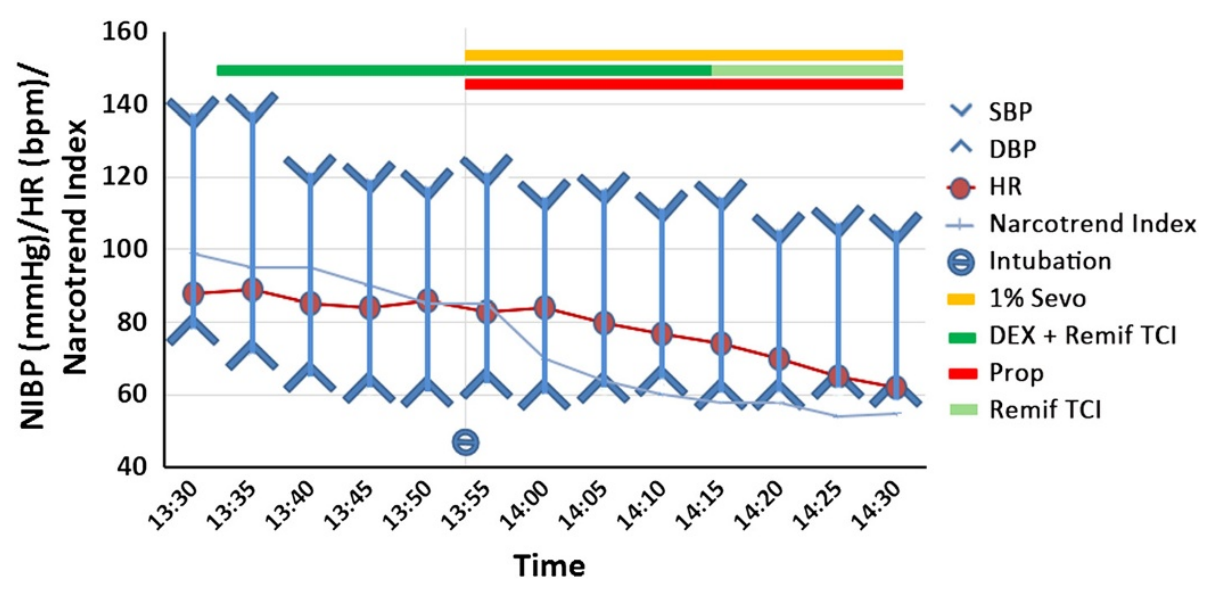

Figure 3 Patient's vital signs and sedation level with Narcotrend ${ }^{\oplus}$ electroencephalography analysis. The Narcotrend Index is an electroencephalography (EEG)-derived index ranging from 1 to 100, indicating sedation level from no EEG activity to actively awake, as follows: 70 to 90 , sleeping or mildly sedated; 40 to 70 , anesthetized. DBP, diastolic blood pressure; HR, heart rate; NIBP, non-invasive blood pressure; Prop, propofol; Remif, remifentanil; SBP, systolic blood pressure; Sevo, sevoflurane; TCl, target controlled infusion.

remifentanil together to provide better airway exposure and improve our patient's hemodynamic safety and comfort.

The instruments used in an anticipated difficult airway include a fiberscope, video laryngoscope and light wand. In our case, although a Macintosh laryngoscope could easily have exposed her vocal cord, we expected to find it difficult to enter her trachea. Thus only a fiberscope was feasible to obtain a view of the airway in her trachea.

Another approach for a difficult airway is invasive access to enable ventilation before anesthesia. The American Society of Anesthesiologists difficult airway algorithm defines invasive access as a surgical or percutaneous airway, jet ventilation and retrograde intubation [6]. However, for our patient, because the tumor was located under her vocal cords and covered the anterior cervical region, neither cricothyrotomy nor tracheotomy could be performed.

As a last resort, extracorporeal membrane oxygenation (ECMO) has also been used in situations where ventilation cannot be performed. ECMO can provide support for severe respiratory failure $[7,8]$. The advantage of ECMO is that gas exchange can be entirely supported during surgical procedures on the airway while also providing an apneic unobstructed surgical field [9]. ECMO can successfully circumvent the problem of a difficult airway and avoid the risks of sudden airway compromise when an immediate tracheotomy is not possible [10].

A highly specialized team of ear, nose and throat specialists, thoracic surgeons, anesthesiologists, and operative supporting staff is required in cases of difficult airways or surgeries on the trachea and carina. Malignant lesions involving the carina and tumors arising from the lung with radial immersion of the main bronchus and carina remain a challenge in airway management, both in terms of surgical and anesthetic consideration. Every so often, pneumonectomy, carinal resection and complicated reconstruction are required to establish airway continuity. Careful assessment and operative planning by both the surgeons and anesthesia team are essential for optimal results [11].

\section{Conclusion}

In cases of extreme airway stenosis, intubation can be safely achieved with dexmedetomidine sedation and remifentanil analgesia.

\section{Consent}

Written informed consent was obtained from the patient for publication of this case report and accompanying images. A copy of the written consent is available for review by the Editor-in-Chief of this journal.

\section{Competing interests}

The authors declare that they have no competing interests.

\section{Authors' contributions}

ZBZ did literature research and drafted the manuscript. XYY participated in coordination and helped prepare the manuscript. XZ collected the patient's data and did the graphical design. SHW obtained the patient's CT scan and $X$-ray photo and helped with graphical design. YX assisted with topical anesthesia and intravenous drug administration and revised the manuscript. XF performed the intubation and did the final revision of the manuscript. All authors read and approved the final manuscript.

Received: 8 February 2014 Accepted: 21 July 2014

Published: 4 September 2014

\section{References}

1. Toyota K, Uchida H, Ozasa H, Motooka A, Sakura S, Saito Y: Preoperative airway evaluation using multi-slice three-dimensional computed tomography for a patient with severe tracheal stenosis. $\mathrm{Br} J$ Anaesth 2004, 93:865-867.

2. Pean D, Floch H, Beliard C, Piot B, Testa S, Bazin V, Lejus C, Asehnoune K: Propofol versus sevoflurane for fiberoptic intubation under spontaneous 
breathing anesthesia in patients difficult to intubate. Minerva Anestesiol 2010, 76:780-786.

3. Chen $L, Y u L$, Fan $Y$, Manyande A: A comparison between total intravenous anaesthesia using propofol plus remifentanil and volatile induction/maintenance of anaesthesia using sevoflurane in children undergoing flexible fibreoptic bronchoscopy. Anaesth Intensive Care 2013, 41:742-749.

4. Tsai CJ, Chu KS, Chen TI, Lu DV, Wang HM, Lu IC: A comparison of the effectiveness of dexmedetomidine versus propofol target-controlled infusion for sedation during fibreoptic nasotracheal intubation. Anaesthesia 2010, 65:254-259.

5. Zhang X, He W, Wu X, Zhou X, Huang W, Feng X: TCl remifentanil vs. TCl propofol for awake fiber-optic intubation with limited topical anesthesia. Int I Clin Pharmacol Ther 2012, 50:10-16.

6. Apfelbaum JL, Hagberg CA, Caplan RA, Blitt CD, Connis RT, Nickinovich DG, Hagberg CA, Caplan RA, Benumof JL, Berry FA, Blitt CD, Bode RH, Cheney FW, Connis RT, Guidry OF, Nickinovich DG, Ovassapian A, American Society of Anesthesiologists Task Force on Management of the Difficult Airway: Practice guidelines for management of the difficult airway: an updated report by the American Society of Anesthesiologists Task Force on Management of the Difficult Airway. Anesthesiology 2013, 118:251-270.

7. Hsu HH, Ko WJ, Chen JS, Lin CH, Kuo SW, Huang SC, Lee YC: Extracorporeal membrane oxygenation in pulmonary crisis and primary graft dysfunction. J Heart Lung Transplant 2008, 27:233-237.

8. Srivastava MC, Ramani GV, Garcia JP, Griffith BP, Uber PA, Park MH: Veno-venous extracorporeal membrane oxygenation bridging to pharmacotherapy in pulmonary arterial hypertensive crisis. J Heart Lung Transplant 2010, 29:811-813.

9. Smith IJ, Sidebotham DA, McGeorge AD, Dorman EB, Wilsher ML, Kolbe J: Use of extracorporeal membrane oxygenation during resection of tracheal papillomatosis. Anesthesiology 2009, 110:427-429.

10. Shao Y, Shen M, Ding Z, Liang Y, Zhang S: Extracorporeal membrane oxygenation-assisted resection of goiter causing severe extrinsic airway compression. Ann Thorac Surg 2009, 88:659-661.

11. Blasberg JD, Wright CD: Surgical considerations in tracheal and carinal resection. Semin Cardiothorac Vasc Anesth 2012, 16:190-195.

\section{Submit your next manuscript to BioMed Central and take full advantage of:}

- Convenient online submission

- Thorough peer review

- No space constraints or color figure charges

- Immediate publication on acceptance

- Inclusion in PubMed, CAS, Scopus and Google Scholar

- Research which is freely available for redistribution 